\title{
Identifying an Appropriate Forecasting Model for Forecasting Total Import of Bangladesh
}

\author{
Tanvir Khan
}

\begin{abstract}
Forecasting future values of economic variables are some of the most critical tasks of a country. Especially the values related to foreign trade are to be forecasted efficiently as the need for planning is great in this sector. The main objective of this research paper is to select an appropriate model for time series forecasting of total import (in taka crore) of Bangladesh. The decision throughout this study is mainly concerned with seasonal autoregressive integrated moving average (SARIMA) model, Holt-Winters' trend and seasonal model with seasonality modeled additively and vector autoregressive model with some other relevant variables. A try was made to derive a unique and suitable forecasting model of total import of Bangladesh that will help us to find forecasts with minimum forecasting error.
\end{abstract}

Index Terms-Arima model, forecasting accuracy Holt Winters' trend and seasonality method, Out of sample accuracy measurement.VAR model.

\section{INTRODUCTION}

An important economic concept involves international trade and finance. International trade in goods and services allows nation to raise their standards of living by exporting and importing goods and services. In a modern economy the economic condition is highly affected by the amount of its foreign trade and its balance of trade. Imports, along with exports, form the basis of trade. Bangladesh has had a negative trade balance since its independence, and the gap between export and import are still widening. The country is importing a lot of goods from the foreign countries and the aim of this paper is to find a forecasting model that will help us to get ideas about the future values of total import of Bangladesh.

\section{DATA AND VARIABLES}

This study is conducted on total import of Bangladesh. The data set have 133 observations, during the time period July 1998 to July 2009, in the initialization set and 14 observations, during the time period August 2009 to September 2010, in the test set. For vector autoregressive model two more variables- total export and net foreign asset, are also used. The data were obtained from the following sources for validation:

1) Statistical Department of Bangladesh Bank

2) 'Economic Trends', a monthly report published by Bangladesh Bank.

Manuscript received January 4, 2011.

Tanvir Khan, MS Student, Institute of Statistical Research and Training, University of Dhaka, Bangladesh (tkhan1@isrt.ac.bd).

\section{METHODOLOGY}

In this study three methods are used, i.e. seasonal ARIMA model, Holt Winters' trend and seasonality method and vector autoregressive model. The goal is to find an appropriate model that has both in sample and out of sample forecasting errors as small as possible.

\section{A. Arima Model}

A model containing $\mathrm{p}$ autoregressive terms and $\mathrm{q}$ moving average terms is classified as $\operatorname{ARMA}(p, q)$ model. If the series is differenced $d$ times to achieve stationary, the model is classified as $\operatorname{ARIMA}(\mathrm{p}, \mathrm{d}, \mathrm{q})$, where the symbol ' $\mathrm{I}$ ' signifies 'integrated'. The equation for the ARIMA (p, d, q) model is as follows:

$Y_{t}=c+a_{1} Y_{t-1}+a_{2} Y_{t-2}+\ldots+a_{p} Y_{t-p}+e_{t}-b_{1} e_{t-1}-$

$b_{2} e_{t-2}-\ldots . e_{t-q}$

Or, in backshift notation:

$$
\begin{gathered}
\left(1-a_{1} L-a_{2} L^{2}-\ldots a_{p} L^{p}\right)(1-L) Y_{t} \\
\quad=c \\
\quad+\left(1-b_{1} L-b_{2} L^{2}\right. \\
\left.\quad-\ldots .-b_{q} L^{q}\right) e_{t}
\end{gathered}
$$

The ARIMA notation can be extended readily to handle seasonal aspects, and a Seasonal ARIMA (p,d,q)(P,D,Q) or SARIMA model can be represented as-

$$
\begin{aligned}
\left(L-L^{2}-L^{3}-\ldots\right. & \left.L^{d}\right)\left(1-L^{S}-L^{2(S)}-\ldots \ldots L^{D(S)}\right)(1 \\
& \left.-a_{1} L-a_{2} L^{2}-\ldots a_{p} L^{p}\right)(1 \\
& \left.-A_{1} L-A_{2} L^{2} \ldots A_{P} L^{P}\right) Y_{t} \\
& =\left(1-b_{1} L-b_{2} L^{2}-\ldots .-b_{q} L^{q}\right)(1 \\
& \left.-B_{1} L-B_{2} L^{2}-\ldots-B_{Q} L^{Q}\right)
\end{aligned}
$$

\section{B. Holt Winters Trend and Seasonality Method}

The Holt-Winters' method is based on three smoothing equations-one for the level, one for trend, and one for seasonality. In fact there are two different Holt-Winters' methods, depending on whether seasonality is modeled in an additive or multiplicative way. The basic equations for Holt-Winters' multiplicative method is as follows:

$$
\begin{aligned}
& \text { Level: } L_{t}=\alpha \frac{Y_{t}}{S_{t-s}}+(1-\alpha)\left(L_{t-1}+b_{t-1}\right) \\
& \text { Trend: } b_{t}=\beta\left(L_{t}-L_{t-1}\right)+(1-\beta) b_{t-1} \\
& \text { Seasonal: } S_{t}=\gamma \frac{Y_{t}}{L_{t}}+(1-\gamma) S_{t-s} \\
& \text { Forecast: } F_{t+m}=\left(L_{t}+b_{t} m\right) S_{t-s+m}
\end{aligned}
$$


where, $s$ is the length of seasonality (e.g. number of month or quarter in a year). $L_{t}$ represents the level of the series, $b_{t}$ represents the trend, $S_{t}$ is the seasonal component, and $F_{t+m}$ is the forecast for $\mathrm{m}$ period ahead. The first two equations for additive model are identical to the first two equations of the multiplicative method. The only difference is in the third equation, that is the seasonal indices are now added and subtracted i.e.:

Seasonal: $S_{t}=\gamma\left(Y_{t}-L_{t}\right)+(1-\gamma) S_{t-s}$

\section{VAR Model}

In a VAR model I have to include the variables which have bilateral causality with each other. A VAR model consists of a set of variables $Y_{t}=\left(Y_{1 t}, Y_{2 t}, \ldots, Y_{K t}\right)$ which can be represented as:

$Y_{t}=\alpha+A_{1} Y_{t-1}+A_{2} Y_{t-2}+\ldots+A_{p} Y_{t-p}+u_{t}$

With $A_{i}$ are $(\mathrm{K} \times \mathrm{K}) \quad$ coefficient matrix for $\mathrm{i}=1,2, \ldots . \mathrm{p}$ and $u_{t}$ is a $\mathrm{K}$ dimensional process with $\mathrm{E}\left(u_{t}\right)=0$ and covariance matrix $E\left(u_{t} u_{t}^{T}\right)=\sum_{u}$.If $Y_{t}$ 's are cointegrated the VAR model can be rewritten as VECM:

$\Delta Y_{t}=\Pi Y_{t-p}+\sum_{i=1}^{P-1} \Gamma_{i} \Delta Y_{t-i}+u_{t}$

where

$$
\Pi=-\left(I-A_{1}-A_{2} \ldots A_{p}\right) \text { and } \Gamma_{i}=-\left(I-A_{1}-A_{2} \ldots A_{i}\right)
$$

If the coefficient matrix $\Pi$ has reduced rank $\mathrm{r}<\mathrm{k}$, then there exist $\mathrm{k} \times \mathrm{r}$ matrices $\alpha$ and $\beta$ each with rank $\mathrm{r}$ such that $\Pi=\alpha \beta^{\prime}$ and $\beta^{\prime} Y_{t}$ is stationary. $\mathrm{r}$ is the number of cointegrating relations and each column of $\beta$ is the cointegrating vector.

\section{Comparison among the forecasting methods}

To make comparison among the methods some well known measures of forecast error are used. The model that gives the minimum measures of these errors will be the expected model for further forecasting. The measures used are cited below;

Mean Error (ME): The mean error gives the average forecast error, i.e. :

$$
M E=\frac{1}{n} \sum_{i=1}^{n} e_{t}
$$

where, $e_{t}=Y_{t}-F_{t}$

$Y_{t}=$ The observation at time $\mathrm{t}, F_{t}=$ Forecasted value at time $\mathrm{t}, \mathrm{n}=$ the number of observation.

Mean Absolute Error (MAE): The MAE is first defined by making each error positive by taking its absolute value, and then averaging the result, i.e. :

$$
M A E=\frac{1}{n} \sum_{i=1}^{n}\left|e_{t}\right|
$$

Mean Squared Error (MSE): The MSE is defined as

$$
M S E=\frac{1}{n} \sum_{i=1}^{n} e_{t}^{2}
$$

Mean Percentage Error (MPE): The MPE is the mean of the relative or percentage error and is given by:

$M P E=\frac{1}{n} \sum_{i=1}^{n} P E_{t} ;$ where $P E_{t}=\frac{Y_{t}-F_{t}}{Y_{t}} \times 100$ is the relative or percentage error at time $t$.
Mean Absolute Percentage Error (MAPE): The MAPE is defined as:

$$
M A P E=\frac{1}{n} \sum_{i=1}^{n}\left|P E_{t}\right|
$$

\section{E. Out of Sample Accuracy Measurement}

The summary statistics described so far measures the goodness of fit of the model to historical data. Such fitting does not necessarily imply good forecasting. An MSE or MAPE of zero can always be obtained in the fitting phase by using a polynomial of sufficiently high order. These problems can be overcome by measuring true out of sample forecast accuracy. That is, the total data are divided into an 'initialization' set and a 'test' set or 'holdout' set. Then the initialization set is used to estimate any parameters and to initialize the method. Forecasts are made for the test set. The accuracy measures are computed for the errors in the test set only.

\section{ANALYSIS OF DATA}

The initialization set of the data has 133 data points, starting from July 1998 to July 2009. The first step of the analysis is to plot the whole dataset to visualize the nature of it. The time plot for total import (in taka crore) of Bangladesh is shown in the figure given below:

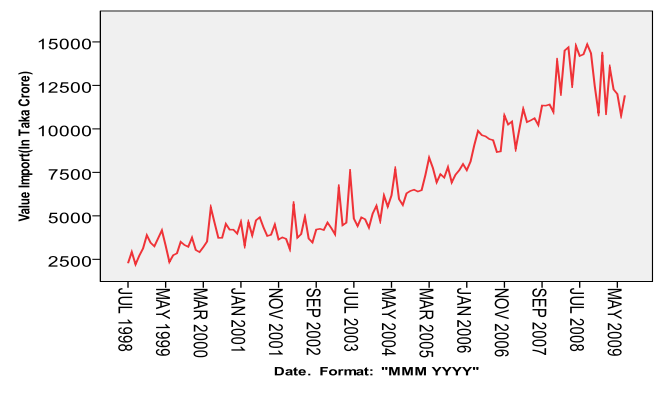

Figure 1: Time series plot for actual data

\section{A. ARIMA Model}

From Figure 1 it can be seen that the data had an upward trend but from October 2008 it started to show a downward trend. From simple view of the plot we can have idea about non stationarity in mean but stationarity in variance. To be surer about stationarity of the data, Augmented Dickey Fuller test was conducted. The calculated value of Dickey Fuller is -2.0622 with $P$ value .5506 at suggested lag 5. So, we fail to reject the null hypothesis of nonstationary. The PACF of the data and ACF of the first differenced data are:

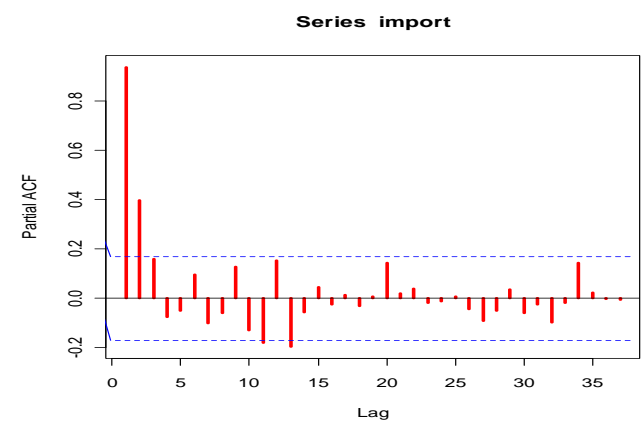

(a) 


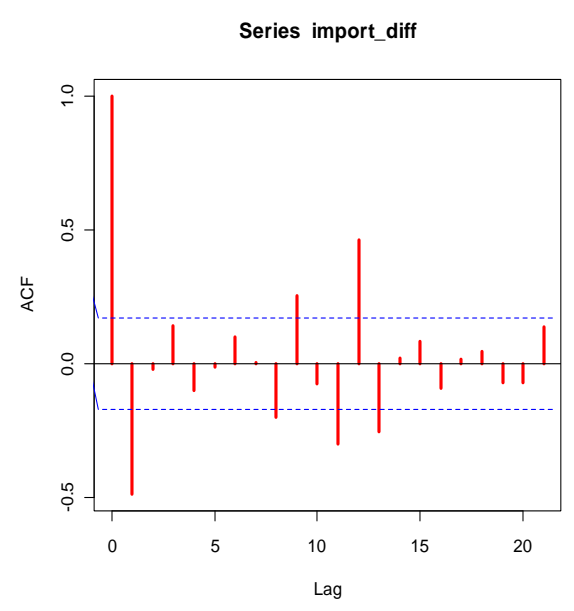

(b)

Figure 2: PACF of original data (a) and ACF of first differenced data (b)

From the PACF plot it can be seen that the partial autocorrelation at lag 12 is insignificant and so are at further seasonal lags (i.e. 24, 36 etc.). So, it can be assumed that the data does not have strong seasonality.

To obtain stationarity the original data are differenced at order one. As the data set do not have strong seasonality, a first order non seasonal difference is taken rather than a seasonal difference and ADF test is conducted again. The value of Dickey Fuller for the first differenced data is 5.3819 with $\mathrm{P}$ value less than .01 at suggested lag 5. This clearly indicates that our data is now stationary. The ACF plot of the first differenced data shows significant spikes at lag 12 , which gives a clear indication that a seasonal term must be included in the model. To be sure about the form of the appropriate model, the AIC and BIC values are checked for all the probable models and it is found that ARIMA $(0,1,1),(1,0,0)[12]$ model has the smallest AIC and BIC values, so, this model should be the desired ARIMA model. The estimated ARIMA $(0,1,1)(1,0,0) 12$ model is given below:

$\widehat{M}_{t}=0.4733 M_{t-12}-M_{t-1}+0.4733 M_{t-13}+$ $.5088 e_{t-1}$

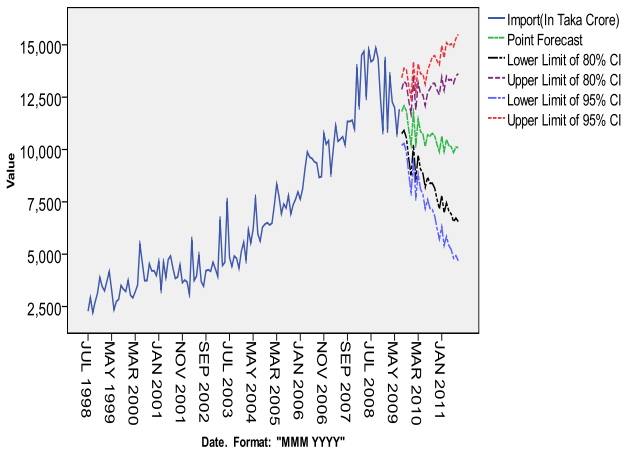

Figure 3: Point and interval forecasting with ARIMA $(0,1,1)(1,0,0) 12$ model

The value of Box-Pierece Q statistic 30.6526 is with degrees of freedom 42 with $P$ value .9026 at lag 44 . So, the null hypothesis that residuals of ARIMA $(0,1,1)(1,0,0) 12$ model are white noise is failed to reject. Again the value of Ljung-Box Q statistic 36.4945 is with degrees of freedom 42 with $P$ value 0.7107 at lag 44 . So, it can be said that the residuals are white noise for $\operatorname{ARIMA}(0,1,1)(1,0,0) 12$ model. The plot of forecasted value along with the original time series is shown in Figure 3.

\section{B. Holt Winters Trend and Seasonality Method}

To initialize the Holt-Winters' forecasting method, initial values of the level $L_{t}$, the trend $b_{t}$, and the seasonal indices $S_{t}$ are needed. To determine initial estimates of the seasonal indices 12 data points were used as the data set is monthly. The estimated model is-

$$
\begin{aligned}
& \quad L_{t}=.3925046\left(M_{t}-S_{t-12}\right)+(1-.3925046)\left(L_{t-1}+\right. \\
& \left.b_{t-1}\right) \\
& b_{t}=b_{t-1} \\
& S_{t}=0.8301905\left(M_{t}-L_{t}\right)+(1-0.8301905) S_{t-12}
\end{aligned}
$$

The plot of forecasted value obtained from Holt Winters model is given below-

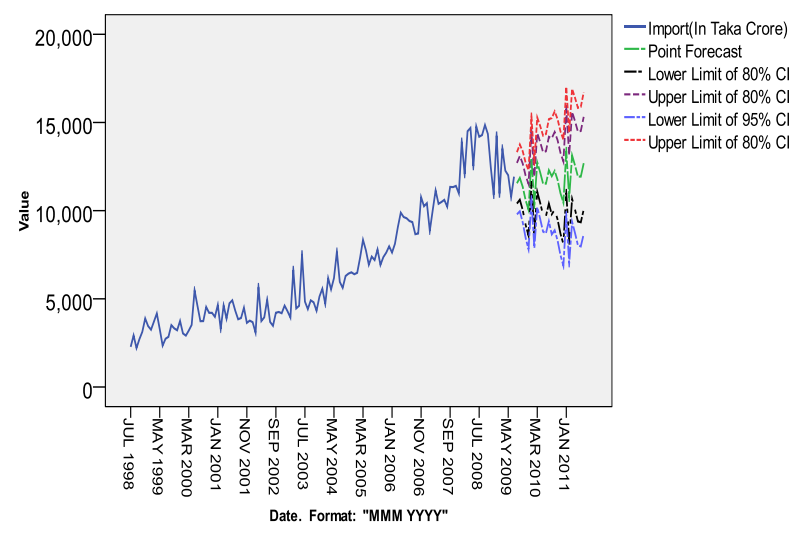

Figure 4: Point and Interval Forecasts obtained from Holt-Winters Model

\section{VAR Model}

To fit a VAR model, at first a try was made to find relevant variables that have bilateral causality with total import of Bangladesh as well as with each other. Primarily 5 variables were chosen. They are -total export, net foreign asset, domestic credit, exchange rate and inflation rate. Among these variables it was found that only total export and net foreign asset have bilateral relationship with each other as well as with total import. The results or Granger causality tests are given below:

TABLE I: RESULT OF GRANGER CAUSALITY TEST

\begin{tabular}{|c|c|c|c|}
\hline \hline relationship & Lag & F-statistic & P-value \\
\hline Export $\rightarrow$ Import & 3 & 3.1070343 & $2.901318 \mathrm{e}-02$ \\
Import $\rightarrow$ Export & 3 & 7.5056727 & $1.180776 \mathrm{e}-04$ \\
NFA $\rightarrow$ Import & 5 & 2.582494 & $2.966103 \mathrm{e}-02$ \\
Import $\rightarrow$ NFA & 5 & 2.460508 & $3.696343 \mathrm{e}-02$ \\
Export $\rightarrow$ Import & 9 & 2.758777 & 0.0061726486 \\
Import $\rightarrow$ Export & 9 & 2.954010 & 0.0036209259 \\
NFA $\rightarrow$ Export & 9 & 3.881317 & 0.0002814135 \\
Export $\rightarrow$ NFA & 9 & 2.346345 & 0.0187481360 \\
\hline \hline
\end{tabular}

So, it can be assumed that total export and net foreign asset can be used as endogenous variables with total import in the desired VAR model. The natural log forms of all the three variables are taken and for dealing with seasonality all the three variables are seasonally adjusted by the 
classical multiplicative decomposing method. The modified data set are then analyzed.

As all the three variables are found I (1), Johansen cointegration test is conducted to check the existence of cointegration and as at lag 2 the model gives the smallest AIC, FP and HQ values, it is fitted with lag 2 and the results are-

TABLE II: RESULT OF JOHANSEN COINTEGRATION TEST BASED ON TRACE STATISTICS

\begin{tabular}{|l|l|l|l|l|}
\hline \hline $\begin{array}{l}\text { Null } \\
\text { hypothesis }\end{array}$ & $\begin{array}{l}\text { Test } \\
\text { statistics }\end{array}$ & $\begin{array}{c}10 \text { percent } \\
\text { critical } \\
\text { value }\end{array}$ & $\begin{array}{c}5 \text { percent } \\
\text { critical } \\
\text { value }\end{array}$ & $\begin{array}{l}\text { 1percent } \\
\text { critical value }\end{array}$ \\
\hline $\mathrm{r} \leq 2$ & 7.69 & 7.52 & 9.24 & 12.97 \\
$\mathrm{r} \leq 1$ & 19.53 & 17.85 & 19.96 & 24.60 \\
$\mathrm{r}=0$ & 63.62 & 32.00 & 34.91 & 41.07 \\
\hline \hline
\end{tabular}

TABLE III: RESULT OF JOHANSEN COINTEGRATION TEST BASED ON MAXIMUM EIGEN VALUE STATISTICS

\begin{tabular}{|l|l|l|l|l|}
\hline \hline $\begin{array}{l}\text { Null } \\
\text { hypothesis }\end{array}$ & $\begin{array}{l}\text { Test } \\
\text { statistics }\end{array}$ & $\begin{array}{c}10 \text { percent } \\
\text { critical }\end{array}$ & $\begin{array}{c}5 \text { percent } \\
\text { critical }\end{array}$ & $\begin{array}{l}\text { 1percent } \\
\text { critical value }\end{array}$ \\
\hline & & value & value & \\
$\mathrm{r} \leq 2$ & 7.69 & 7.52 & 9.24 & 12.97 \\
$\mathrm{r} \leq 1$ & 11.83 & 13.75 & 15.67 & 20.20 \\
$\mathrm{r}=0$ & 44.09 & 19.77 & 22.00 & 26.81 \\
\hline \hline
\end{tabular}

Both of the above procedures reveal that there is one cointegrating relationship among the variables. So, the rank of $\Pi$ in the equation 10 is 1 . This model is then converted into level VAR (using R statistical software's package vars) for forecasting. The coefficient matrix of the first order lagged variables of the estimated model is-

$$
\left[\begin{array}{ccc}
0.3953967 & -0.09113555 & -0.02662601 \\
0.1315107 & 0.39966812 & 0.20584631 \\
-0.1271218 & 0.12755932 & 1.08941860
\end{array}\right]
$$

And the coefficient matrix for the second order lagged

$$
\left[\begin{array}{ccc}
-0.03251774 & 0.59662961 & 0.1255279 \\
-0.03792212 & 0.52607838 & -0.2203743 \\
0.02665503 & -0.04784865 & -0.0738229
\end{array}\right]
$$

Coefficient matrix of deterministic repressor is-

$$
\left[\begin{array}{c}
0.45949625 \\
-0.05045786 \\
0.08285586
\end{array}\right]
$$

At lag 31, asymptotic Portmanteau test has the ChiSquare value 270.3135 with $P$ value 0.6811 , and the adjusted Portmanteau test has Chi-Square value 312.037 with $\mathrm{P}$ value 0.1056 .So, the model has white noise residuals.

The value of Chi-Squared for the multivariate $\mathrm{ARCH}$ test at lag 5 is 203.1458 with $\mathrm{P}$ value 0.1139 . So, no conditional heteroscedasticity is present in this model.

The forecasted values of the model are then back transformed to get the forecasted values of total imports of Bangladesh.

The plot of original data and forecasted values is:

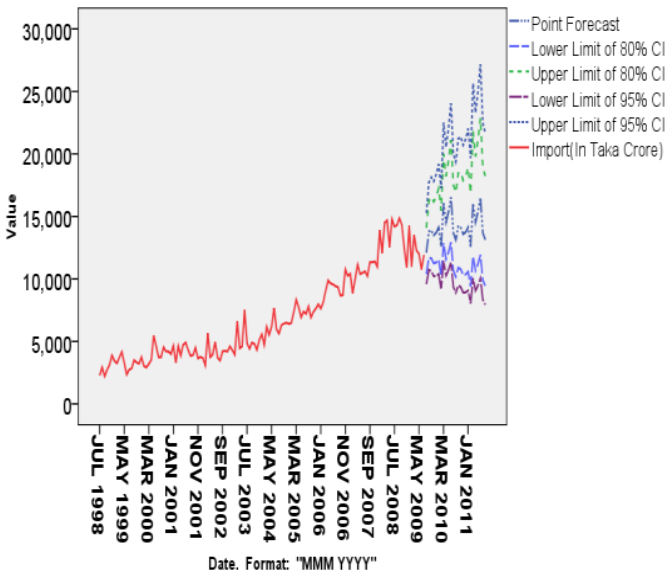

Figure 5: Point and Interval Forecasts obtained from VAR model

\section{COMPARISON AMONG ARIMA, HOLT WINTERS TREND AND SEASONALITY METHOD AND VAR MODEL}

The forecasting performance of these three models have been compared with each other with respect to different measures of error and the summary measures are listed in the table IV-

TABLE IV: IN SAMPLE ERROR MEASURES OF THE METHODS

\begin{tabular}{|c|c|c|c|}
\hline \hline $\begin{array}{c}\text { Measures of } \\
\text { Error }\end{array}$ & $\begin{array}{c}\text { ARIMA } \\
(0,1,1)(1,0,0) 12\end{array}$ & $\begin{array}{c}\text { Holt-Winters' } \\
\text { Method }\end{array}$ & $\begin{array}{c}\text { VAR } \\
\text { Model }\end{array}$ \\
\hline ME & 58.61606930 & 80.57279 & 29.68408 \\
MAE & 588.55960438 & 676.039 & 630.97 \\
MSE & 671123.9 & 808836.5 & 789098.7 \\
MPE & 0.01089789 & 0.08561744 & -0.542072 \\
\hline MAPE & 9.48140336 & 10.56153 & 9.230532 \\
\hline
\end{tabular}

In sample error measures don't necessarily imply good forecasting model. To find which forecasting method is better, true out of sample forecast accuracy was measured.

The plot of the test set observations with the forecasted values using all three methods is given -

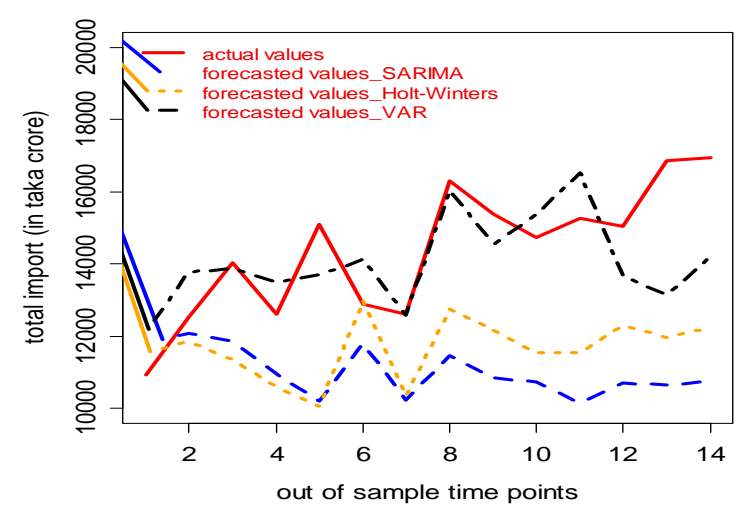

Figure 6: Plot of test set of the data and forecasted values obtained from the three methods

The out of sample accuracy measures are given below: 
TABLE V: OUT OF SAMPLE ACCURACY MEASUREMENTS

\begin{tabular}{|c|c|c|c|}
\hline \hline $\begin{array}{c}\text { Measures } \\
\text { of Error }\end{array}$ & $\begin{array}{c}\text { ARIMA } \\
(0,1,1)(1,0,0) \\
12\end{array}$ & $\begin{array}{c}\text { Holt- } \\
\text { Winters' } \\
\text { Method }\end{array}$ & VAR Model \\
\hline ME & 3350.570 & 2712.007 & 291.0543 \\
MAE & 3477.229 & 2815.95 & 1210.929 \\
MSE & 15747374 & 10227508 & 2379564 \\
MPE & 61.09258 & 17.79637 & 1.079790 \\
& 22.97802 & 18.72796 & 8.209862 \\
MAPE & & & \\
\hline \hline
\end{tabular}

From the above table it is clear that VAR model is giving minimum values for all the measures of forecast error. So, one may take VAR model of total import, total export and net foreign asset as an appropriate model for forecasting total import of Bangladesh.

\section{CONCLUSION}

The basic aim of this paper is to select an appropriate model that will be helpful for understanding future behavior of total import of Bangladesh. Three methods are used- seasonal ARIMA, Holt-Winters' trend and seasonality method and VAR model. Various measures of forecasting accuracy were also measured for all the three models. The comparison shows that VAR model of total import with total export and net foreign asset as other endogenous variables is better than the other two methods as it is producing both in sample and out of sample forecasting errors. But this is not the end. More researches have to be done to handle seasonality in a better way and to find the more relevant variables that are useful for forecasting total import of Bangladesh.

\section{REFFERENCES}

[1] Amisano, G. and Giannini, C. (1997). Topics in Structural VAR Econometrics, Springer-Verlag, Berlin, $2^{\text {nd }}$ edition.

[2] Gujrati, D. N. and Sangeetha (2007). Basic Econometrics, McGrawHill Book Co, New York.

[3] Hamilton,J.D. (1994). Time Series Analysis, Princeton University Press, Princeton.

[4] [4] Lutkepohl, H. (2006). New Introduction to Multiple Time Series Analysis. Springer-Verlag, New York.

[5] Makridakis, S., Wheelwritght, S. C. and Hyndman, R. J. (1998). Forecasting Methods and Applications, John Wiley and Sons, Ink., New York.

[6] Pfaff, B. (2006). Analysis of Integrated and Cointegrated Time Series with R. Springer-Verlag, New York.

[7] Pfaff, B. (2008). VAR, SVAR and SVEC Models: Implementation within R Package vars, New York. URL: http://CRAN.Rproject.org/package=vars. 